\title{
World Health Report 2000: Health system performance
}

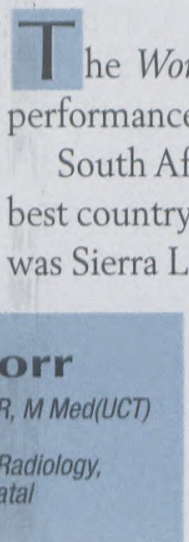

\section{Peter Corr}

$M B C h B$, FFRad(D)SA, FRCR, M Med(UCT)

Head: Department of Radiology, University of Natal

South Africa's health system measured poorly in the following areas of responsiveness to people's expectations: promptness of service delivery, choice of service provider, respect of patients and institutional autonomy.

For radiologists, an interesting comparison was the health care input mix in middle-income countries like South Africa, Thailand, Mexico and Egypt. Health care input mix is a measure of the financial resources invested in high technology such as MR and CT scanners, finance spent on hospital beds and finance spent on training of physicians and nurses. The authors' comment on South Africa is that it is "at the maximum of the group of middle income countries for expenditure on health care, nurses, hospital beds and MR scanners, while it is the furthest from the maximum for drugs and physicians".

What does this all mean in a global perspective? We are classified by the World Bank as a middle-income country. Our gross national product per capita in 1998 was USD3 310, making us the 83 rd richest country in the world $!^{2}$ We spend close to $8,5 \%$ of our gross domestic product (GDP) on health care, which compares well with other middle-income countries: $6 \%$ in Hungary, $3 \%$ in Malaysia and 4,7\% in Chile, all of which have better performing health systems. ${ }^{3}$

What is apparent is that we are not getting value for money in our health care system investment in South Africa. Now that our health system performance has been measured for the first time using international norms, we know where we stand in the international rankings. We also know we have to do better.

\section{Peter Corr}

Editor

\section{References}

1. World Health Report 2000. Health systems: Improving performance. Geneva: WHO, 2000 (www.who.org).

2. World Bank Atlas 2000. Washington: World Bank (www.worldbank.org).

3. McIntyre D, Bloom G, Doherty J, Brijlal P. Health expenditure and finance in South Africa. Durban: Health Systems Trust \& World Bank, 1993 (www.hst.org.za/pubs/hstefsa/heftoc.htm). 